\title{
The Prevalence of Anaemia Among Children Age 6 to 59 Months and Association Factors in Central Highland Region of Ethiopia, Community Based Cross Sectional Design, Initial Assessment for BCC Intervention
}

\author{
Abebe Ferede, MSc \\ Arsi University, College of Health Science, \\ Department of Public Health, Asella, Ethiopia \\ Muluemebet Abera, MSc, PhD \\ Professor Tefera Belachew, MD, MSc, PhD \\ Jimma University, Faculty of Public Health, \\ Department of Population and Family Health, Jimma, Ethiopia
}

URL:http://dx.doi.org/10.19044/esj.2019.v15n9p34

\begin{abstract}
Behavioral change communication (BCC) to prevent iron deficiency anaemia had lacked attention in our country. Considerably, children are the most vulnerably group for iron deficiency anaemia (IDA). This study aimed to assess prevalence of anaemia and associated factors among children age 6 to 59 months. Methods: Community based Cross sectional study design was used for initial assessment for BCC intervention in Central Highland of Ethiopia. Multistage sampling method was used to select 8 districts, 16 clustered Kebeles (smallest unit of administration) and 1012 mothers/care givers and their pair children age 6 to 59 months by considering feature BCC intervention. Dietary behaviour, anthropometric measurements and blood samples data were collected. Binary and linear logistic regressions were analysed using IBM SPSS Statistics software version 21. Results: The prevalence of anaemia among study subjects was $184(18.4 \%$.), but higher (24.1\%) among group of age 6 to $<24$ months. The mean $\mathrm{Hb}$ concentration was $12.55 \pm 1.73$ and stunted growth $(411(40.6 \%))$. Being consuming cow milk as major complementary food (Adjusted Odds Ratio (AOR) $=4.54,95 \%$ $\mathrm{CI}=3.14,6.56)$, age 6 to $<24$ months ( $\mathrm{AOR}=1.4, \mathrm{CI}=1.10,2.94)$ were considered as independent predictors of risk for having anaemia among children. In linear logistic regression analysis, being increasing age (Bcoefficient $((B)=0.172, C I=0.01,0.33)$ and increasing height $(B=0.170$, $\mathrm{CI}=0.14,0.329)$ were potentially increase haemoglobin concentration by
\end{abstract}


$0.170 \mathrm{mg} / \mathrm{dl}$. Also, Height for age (HAZ) $(\mathrm{B}=0.105, \mathrm{CI}=0.02,0.144)$ change $\mathrm{Hb}$ concentration by $0.105 \mathrm{mg} / \mathrm{dl}$. Conclusions: The magnitude of anaemia was moderate among young children. Cow milk consumption and young children related to poor dietary intake behaviour increased the risk of anaemia and high proportion of inadequate growth (stunting) among study subjects considerable for $\mathrm{BCC}$ intervention to improve iron intake for children growth.

Keywords: Anemia, Children, Dietary behaviour, Central Highland, Ethiopia

\section{Introduction}

Inadequate micronutrient nutritional intake might be one of the several factor that increase the risk of anemia, However childhood time anaemia might have different dietary intake behaviourthat affects young children. Iron deficiency (ID) in children is also associated with impaired mental and physical development. In addition, cognitive disturbances could be caused by ID without anaemia (Black MM, 2003). In children, during infantile period of rapid growth age 2 to 6 months has a high risk of iron deficiency (Hiroko KODAMA, 2004). Many of report agreed over untreated iron deficiency can affect a child's growth and development (Mayo Clinic, 2016).

Iron deficiency is the most prevalent and it is estimated that just over 2 billion people are anaemic (worldwide or?). According to WHO mortality data, around 0.8 million deaths ( $1.5 \%$ of the total) can be attributed to iron deficiency each year. In terms of the loss of healthy life, expressed in disability-adjusted life years (DALYs), iron-deficiency anaemia results in 25 million DALYs lost (or $2.4 \%$ of the global total). According to WHO report, the prevalence of anaemia in African estimated to 244 million [46\%] (WHO, 2002).

Before twenty years ago, ID with anaemia affected $45 \%$ of children aged less than 5 years in developing countries (Grantham et al., 1999). According to WHO global database sources, currently the prevalence of IDA in children 6 to 59 months excesses to $46 \%$ in selected countries in east and southern Africa. From Africa countries, Uganda was leading by $72.6 \%$ (UDHS 2007) followed by Malawi was $625 \%$ (MDHS, 2011). However, a trend analysis for anaemia indicated that in East Africa the trend of anaemia among children aged 6-59 months reducing from 74\% (65-81) in 1995 to 55\% (50-59) in 2011(Gretchen, et al., 2013).

However, few studies have showed significant association between the effect of IDA and children weight and iron supplementation predicted greater increase in weight gain (Aukett et al., 1986). Currently, a significant reduction in prevalence of anaemia was indicated $7 \%$ in developed countries and currently, it is estimated to affect $2 \%-6 \%$ in European children due to 
enhancing enriched foods and the use of supplements which has contributed to that reduction, among other factors (Sánchez et la., 2013).

The link of iron deficiency and children growth has not been clearly signified but a lot of cross sectional studies predicted high prevalence of iron deficiency anaemia among children age under 5 was common (Aukett,2003). In Ethiopia, the prevalence of anaemia was found to be increasing from time to time in children 6 to 59 months. Trend of anaemia at this age group was 54 percent in 2005, 44\% in 2011 and 56\% in 2016. From limited study, a study conducted in districts of Kilte Awulaelo, Northern Ethiopia indicated that about $37.3 \%$ of children were anaemic (Gebremedhin et al., 2014). There were limited studies conducted on child anaemia and associated factors in Ethiopia and where children may suffer from different micronutrient deficiencies but not linked with BCC in dietary intake of iron to prevent child IDA and improve children growth.

In IDA, mostly iron supplementation trials and interventions have become common in the community, but not lay a foundation for behavioural change of the mothers or caregivers on dietary intake of young children. Our initial assessment addressed the past behaviour of mothers/ caregivers in young children feeding and determined nutritional status of the children for $\mathrm{BCC}$ intervention baseline.

\section{Methods}

\section{Study design and area}

Community based Cross sectional study design was used for initial assessment for BCC intervention in Central highland region of Ethiopia from January to July 2018. The area includes Arsi and Bale provinces (Munesa, Asella, Limuna Bilalo, Digeluna Tijo, Honkolo Wabe) mountains areas and has an altitude of above 2400 meter and had history of annual mean rainfall of $2200 \mathrm{~mm}$ to $2350 \mathrm{~mm}$ (Aklilu et al, 2013).

\section{Study population}

All mothers or care givers who had children aged 6 to 59 months and lived in the selected kebles found in central highlands of Ethiopia constituted the study population. One hundred and twelve mothers with their pair children 6 to 59 months were included as study subjects.

\section{Sample size estimation:}

Sample size was determined using Gpower computer software version 3.0 and through consideration of future BCC intervention. 
Analysis: Sensitivity: Compute required effect size

$\begin{array}{ll}\text { Tails } & =\text { Two } \\ \alpha \text { err probability } & =0.05 \\ \text { Power }(1-\beta \text { err probability }) & =0.95\end{array}$

Output: Total sample size $=1012$

Note Book: The sample size was determined by considering feature BCC intervention.

\section{Sampling procedure}

Multistage sampling method was used to select 8 districts, 16 Kebeles (smallest unit of administration) and from the Central Highland region of Ethiopia. In the first stage, five distracts and 3 rural towns were included and from these, 16 clustered Kebeles were randomly selected. At the final stage, 1012 mothers/care givers and their pair children aged 6 to 59 months were selected with systematic random sampling. Breast feeding, starting time of complementary food, past feeding method and food types usually dietary intake by individual child during infantile and childhood period were assessed using structured interviewer administered questionnaire.

Blood test for hemoglobin: Trained laboratory technologists collected each child's blood sample and analyzed. Hemoglobin concentration was determined using HemoCue $\mathrm{Hb} 301{ }^{\circledR}$. Each participant's hand was warmed and relaxed. Study participant's mother or guardian was informed about required blood sample from child to analyse hemoglobin concentration, the need safe and precise finger prick at child's finger to prevent minimum risk. Consequently, after mother / guardian agreed, she was asked to comfortably hold her child firmly, and immobilise the finger to be punctured, to prevent sudden movement and accidental injury.

Analyzed hemoglobin results were adjusted for altitude and categorized into no Anaemia $(\mathrm{Hb}>11 \mathrm{~g} / \mathrm{dl})$, normal, anaemic $(\mathrm{Hb}<11 \mathrm{~g} / \mathrm{dl})$, unhealthy and clinical anaemia was observed with $\mathrm{Hb}<7 \mathrm{~g} / \mathrm{dl}$ as sever $\mathrm{Hb}$ (WHO, 2011).

Anthropometric measurements: weight and height measurements were taken and calculated for weight for height $\mathrm{Z}$ score (WHZ) to measure thinness and height for age $\mathrm{Z}$ score (HAZ) to measure children growth that to be more interpreted with WHO reference (WHO, 1995).

Weight measured in kilogramme without shoes and with slight cover dress, using a battery-powered digital scale for children for those whom able to stand and hanging spring scale for children $<2$ years with a capacity of $100 \mathrm{gm}$ to the nearest $200 \mathrm{gm}$. The weight scale was calibrated to zero before taking the next measurement.

Height was measured with bare feet to the nearest $1 \mathrm{~cm}$ using a stadiometer (a vertical tape fixed perpendicular to the ground on the wall) used 
for children age $\geq 24$ months. Recumbent length board was used for children aged less than 24 months. During measurement, the individual child relaxed with no shoes on and lied parallel to the long axis of the board and then measurement were taken using 2 trained data collectors.

\section{Data processing and analysis}

HAZ and WHZ were analysed using Emergency Nutrition Assessment (ENA) software and communicated according to the World Health Organization (WHO) Child Growth Standards.

Stunting is defined as a malnutrition relevancy of individual height in relation to his/her age (HAZ) $<-2 \mathrm{Z}$ score (standard deviation (SD)). Wasting (thinness) was defined as weight relevant to height (WHZ) $<-2 \mathrm{SD}$ (WHO, 1995).

Data was entered with EpiData: 3.0 version and transferred into Statistical Package for Social Science statistical software for windows, version 21 for analysis. Descriptive statistical methods were used for presenting data by using proportions and frequencies. Bivariate and multivariable logistic regression models were used to identify the likelihood of anaemia among children. Odds ratios with $95 \%$ of confidence intervals (CIs) were computed to assess the presence and degree of association between independent variables and anemia. A p-value less than 0.05 used to declare a statistically significant association with anemia.

Linear regression model was used to assess predictors for positive/ negative or no effect on children's haemoglobin concentration and correlation was declared at beta coefficient (B) and 95\% CI. About the assumptions of linear regression analysis, variables linearity, homoscedasticity and normality of the distribution were checked with scatter plots and histograms. Finally, independence of the predictor variables and the absence of their intercorrelation assessed with collinearity statistics where variance inflation factors (VIF) less than 10 and tolerance greater than 0.1 were used as sign of model fitness.

\section{Results}

A total of 1012 mothers/care givers and their pair children participated in the study with a response rate of $100 \%$. Majority (620 (61.3\%)) of children pair mothers/caregivers were found to have attended elementary level of education or illiterate and $465(45.9 \%)$ were housewifes. Most $(823,(81.3 \%))$ of mothers/caregivers who participated in this study had $<5$ family members and $447(44.2 \%)$ of them had $<1000$ Et Birr considered as monthly income (Table 1). 


\section{Children demography and health care}

About demographic characteristic of the study participants, half (506 $(50 \%)$ ) of the children who participated in the study were younger (aged 6 to $<24$ months) and their average age was.27.27 \pm 14 moths with a median of 24.5 months. Most (548 (54.2\%)) of the children were male (Table 1).

Table 1: Socio-demographic status of mothers and children in Central Highland of Ethiopia

\section{Variables} Frequency $(\mathrm{n}=1012)$

Percent $(\%)$

Age $<20$

Maternal Age

Age 2035

88

8.7

Age $>35$

776

76.7

148

14.6

Illiterate

Education level

Read and write

171

16.9

Primary education

141

13.9

Secondary education

30.3

393

38.8

\section{Marital Status}

Single

Married

919

90.8

Divorced

Widowed

Separated

\section{Occupation}

House wife

Farmer

Business women

Gov.employee

Daily labourer

NGO employee

Student

House servant

None

\section{Family size}

5-8 members 
Monthly income (Et Birr)

$<1000$ Et. Birr

447

484

1000-5,000 Et. Birr

5001-10,000Et. Birr

$>10,000$ Et. Birr

\section{Children sex}

Male

Female

464

Age of the children in month

age $<24$

506

506
45.8

50.0

44.2

47.8

7.7

3.0

50.0

Et Birr, Ethiopian currency: NGO, None Governmental Organisation: n, total study subject.

Concerning the child health care, a high proportion (940 (92.89\%)) of children who participated in the study were found to have completed their PENTA vaccines and 971 (95.9\%) of them were regularly supplied vitamin A. There were 904 (89.3\%) study respondents who had received anti worm (deworming) preventive treatment (Table 2).

\section{Child feeding practices}

Regarding the past history of feeding, majority (888 (87.5\%)) of children went through the first 6 months of their life with breast milk. Regarding the current child feed, 549 (54.2\%) children only depended on cow milk and $503(49.7 \%)$ of the mothers have continued breast-feeding until the time of this study. Concerning the time for starting complementary food for children, majority $(815(80.5 \%))$ of the children introduced immediately on their six months but 388 (38.3\%) of the children introduced with bottle feeding and also currently used this method. There were $808(80.0 \%)$ respondents who had only thrice meal frequency per day and $189(18.7 \%)$ of the children had less than thrice male per day. About dietary diversification, only $184(18.2 \%)$ mothers/caregivers recognised using animal and plant sources of food mutually for as complementary food for children. As regards the consumption of animal organ meat, 718 (70.95\%) mothers/caregivers were well thoughtout to provide for their children (Table 2). 
Table 2: Child feeding, iron rich food intake and healthcare in Central Highland of Ethiopia, 2018

\begin{tabular}{|c|c|c|c|}
\hline Variables & & $\begin{array}{r}\text { Frequency } \\
(\mathrm{n}=1012) \\
\end{array}$ & Percent $(\%)$ \\
\hline \multirow[t]{2}{*}{ Exclusive breast fed for the first 6 months } & Yes & 888 & 87.50 \\
\hline & No & 126 & 12.50 \\
\hline \multirow[t]{4}{*}{ Current feeding method used } & Only breast milk & 95 & 9.40 \\
\hline & Expressed from & 264 & 26.10 \\
\hline & Formula milk & 104 & 10.30 \\
\hline & Cow milk & 549 & 54.20 \\
\hline \multirow[t]{3}{*}{ Time for complementary fed } & On 6 month & 815 & 80.50 \\
\hline & Before 6 months & 111 & 11.00 \\
\hline & After 6 months & 86 & 8.50 \\
\hline \multirow[t]{2}{*}{ Still breast-feeding the child } & Yes & 503 & 49.70 \\
\hline & No & 509 & 50.30 \\
\hline \multirow[t]{2}{*}{ Bottle feeding prohibited } & No & 624 & 61.70 \\
\hline & Yes & 388 & 38.30 \\
\hline \multirow[t]{2}{*}{ PENTA Vaccine Completed } & No & 72 & 7.11 \\
\hline & Yes & 940 & 92.89 \\
\hline \multirow[t]{2}{*}{ Vitamin A supplementation } & No & 41 & 4.10 \\
\hline & Yes & 971 & 95.90 \\
\hline \multirow[t]{2}{*}{ De-worming supplementation } & No & 108 & 10.7 \\
\hline & Yes & 904 & 89.3 \\
\hline \multirow[t]{4}{*}{ Meal frequency per day } & less than thrice & 189 & 18.70 \\
\hline & Thrice & 808 & 80.00 \\
\hline & More than thrice & 13 & 1.30 \\
\hline & Yes & 829 & 81.92 \\
\hline \multirow[t]{2}{*}{ Only cow milk consumption } & No & 512 & 50.59 \\
\hline & Yes & 500 & 49.41 \\
\hline \multirow[t]{2}{*}{ Ripe mangoes/ papayas } & No & 395 & 39.00 \\
\hline & Yes & 617 & 61.00 \\
\hline \multirow[t]{2}{*}{ Had have pineapple } & No & 523 & 51.70 \\
\hline & Yes & 489 & 48.30 \\
\hline \multirow[t]{2}{*}{ Animal organ meat intake } & No & 294 & 29.05 \\
\hline & Yes & 718 & 70.95 \\
\hline \multirow[t]{2}{*}{ Egg intake } & No & 183 & 18.08 \\
\hline & Yes & 829 & 81.92 \\
\hline \multirow[t]{2}{*}{ Dietary diversity recognition } & Yes & 184 & 18.20 \\
\hline & $\mathrm{No}$ & 828 & 81.80 \\
\hline
\end{tabular}

PENTA = five vaccines which have been included in the immunization program.

There are dietary factors that can enhance or inhibit iron rich food absorption from the gut. However, in our study only 236 (23.32\%) mothers/caregivers participated in the study habited consuming fruit after a meal and in contrary $768(75.89 \%)$ had habited to drink tee/ coffee with or after meal (Table 3). 
Table 3: Dietary intake that enhance or inhibit iron rich food absorption among study subjects in Central highlands of Ethiopia, 2018

\begin{tabular}{lccc}
\hline & Variables & $\begin{array}{r}\text { Frequency } \\
(\mathbf{n = 1 0 1 2})\end{array}$ & Percent (\%) \\
\hline Yes & Habited fruit intake after meal & 236 & 23.32 \\
No & Flesh foods intake & 776 & 76.67 \\
& & 321 & 31.72 \\
Yes & & 691 & 68.28 \\
No & Vitamins A rich fruits/vegetables & & \\
& & 676 & 66.80 \\
Yes & Other fruits/vegetables & 336 & 33.20 \\
No & & & \\
& & 534 & 52.77 \\
Yes & Habit of tee/ coffee with or after meal & 478 & 47.23 \\
N o & & 768 & 75.89 \\
& & 244 & 24.11 \\
Yes & Drinking milk with or after meal & & \\
No & & 878 & 86.76 \\
Yes & & 134 & 13.24 \\
No & &
\end{tabular}

Child nutritional status: The mean value of haemoglobin $(\mathrm{Hb})$ for blood samples taken from children who participated in the study was $12.55 \pm 1.73$, while the prevalence of anaemia was $184(18.20 \%)$. The prevalence was higher among children who were younger age 6 to $<24$ had $122(24.1 \%), n=506)$ than older (age 24 to 59 months (62 (12.3\%) n=506). High proportion (411(40.6.3\%)) of children participated in the study were under growth (stunted) referred as HAZ below.-2SD. On other nutritional status assessment, $251(24.8 \%)$ of study participants had low weight for height Z score (WHZ) considered as thin (wasted), but very less proportion (114(11.3\%)) of were experienced acute malnutrition with measurement of Mid Upper Arm Circumference (MUAC) blow $12 \mathrm{~cm}$ (Table 4). 
Table 4: Nutritional status of study subjects in central highland of Ethiopia, 2018

\begin{tabular}{|c|c|c|}
\hline Variables & $n=1012$ & Percent (\%) \\
\hline \multicolumn{3}{|l|}{ Anemia } \\
\hline Yes & 184 & 18.20 \\
\hline No & 828 & 81.80 \\
\hline \multicolumn{3}{|l|}{ HFA Z score (SD) } \\
\hline <-1SD:stunted Growth & 620 & 61.30 \\
\hline $\begin{array}{l}\text { Z-1SD: normal growth } \\
\text { WFH Z score }(\text { SD })\end{array}$ & 392 & 38.70 \\
\hline$\geq-1 S D$ wasting & 251 & 24.80 \\
\hline \multicolumn{3}{|l|}{ MUAC in $\mathrm{cm}$} \\
\hline$<12 \mathrm{~cm}$ & 114 & 11.30 \\
\hline$>12 \mathrm{~cm}$ & 898 & 88.70 \\
\hline
\end{tabular}

$\mathrm{cm}$, centimetre: SD, standard division: HAZ, height-for-age Z score: WFZ, weight for height

$\mathrm{Z}$ score. Note Book: ENA (Emergency Nutrition Assessment) computer software used to calculate these anthropometric measurements.

\section{Association of variables}

In the bivariate logistic regression analysis, children in the age group of 6 to 24 months were more likely to be anaemic than those in the older age groups $(\mathrm{AOR}=1.47,95 \% \mathrm{CI}=1.10,2.94)$ and The probability of having anaemia was higher $(\mathrm{AOR}=1.31,95 \% \mathrm{CI}=1.02,1.85)$ among children who had weight for height (WFA) Z-Score blow-1SD compared to those had WFA Z-score $\geq 1 \mathrm{SD}$. The proportion of anaemia was higher among children who had height for age (HFA) Z-score -1SD ( $\mathrm{AOR}=1.56,95 \% \mathrm{CI}=2.21)$ contrasted to children who had HFA Z-score $\geq 1 \mathrm{SD}$ (Table 5).

Children who were current cow milk users as major complementary food had a risk of anaemia more than 4 times that of non-users. (Adjusted Odds Ratio $(\mathrm{AOR})=4.54,95 \%$ confidence interval $(\mathrm{CI})=3.14,6.56)$. Lack of consuming of animal organ meat $(\mathrm{AOR}=1.78, \mathrm{CI}=1.35,2.45)$, ripe mangoes or papayas fruits $(\mathrm{AOR}=1.48, \mathrm{CI}=1.23,2.11)$ and pineapple $(\mathrm{AOR}=1.56$, $\mathrm{CI}=1.14,2.54)$ were considered as independent predictors of risk for having anaemia among children compared to those who consumed these type of foods (Table 5). 
Table 5: Bivariate and multivariable logistic regression models predicting the likelihood of anaemia among children in Central highland of Ethiopia

\section{Anaemia No anaemia}

Variables

$(\mathrm{Hb}<11 \mathrm{mg} / \mathrm{dl})$

$(\mathrm{Hb} \geq 11 \mathrm{mg} / \mathrm{dl})$

$\operatorname{COR}(95 \% \mathrm{CI})$

$\operatorname{AOR}(95 \% \mathrm{CI})$

$\mathbf{n}(\%)$ n(\%)

\section{Children age}

$\geq 24$ months

$$
62(6.13)
$$

444(43.87)

1

6 to $<24$ months

384(37.94)
$0.67(0.47,0.96)$

1

Maternal / care providers' education status

Primary\& secondary

Illiterate, read/write

WFH Z score
$128(12.65)$

$56(5.53)$

$$
\begin{array}{rr}
162(16.01) & 771(76.19) \\
22(2.17) & 57(5.63)
\end{array}
$$

$572(56.52)$

256(25.30)

1
$1.02(0.72,1.45)$

99(9.78) 502(49.61)

$0.75(0.55,1.08)$
85(8.40) 326(32.21)

481(47.53)

347(34.29)

43(4.25)

141(13.93)

Yes

Consuming animal organ meat

Yes

112(11.07)

606(59.88)

222(21.93)

72(7.11)

Egg intake

No

Yes

144(14.23)

684(67.59)

$145(14.33)$

Ripe mangoes /papayas fruits

No had not

Yes had have

$\begin{array}{rr}84(8.30) & 311(30.73) \\ 100(9.88) & 517(51.09)\end{array}$

100(9.88) 517(51.09)

Pineapple (Ananas cornosus)

Yes

$100(9.88) \quad 415(41.00)$

76(7.50)

413(40.81)

No

Iron and vitamin A-rich foods (food originated ether from meat, liver, fish)

150(14.82) 658(65.02)

34(3.36) $\quad 170(16.80) \quad 1.14(0.75,1.72)$

$1.47(1.10,2.94)^{*}$

Yes

$0.22(0.15,0.31)$

$4.54(3.14,6.56)^{*}$

No

COR, crude odds ratio; AOR, adjusted odds ratio; CI, confidence interval; Hb, Haemoglobin; mg, milligram; dl, Decilitre; WFH, Weight for Height; HFA, Height relative to age; SD, standard deviation; $\mathrm{Z}$ score, Note Book $(\mathrm{NB}) *$ significant $(\mathrm{P}<0.05)$.

In linear regression analysis, the concentration haemoglobin was considered as dependent variable and more than 12 independent explanatory factors of haemoglobin concentration were analysed. Regarding the model summary conformation, adjusted $\mathrm{R}$ square $=0.084$ in which the model 
explains $8.4 \%$ of variations in haemoglobin concentration and also in model summary Durbin-Watson statistic showed that haemoglobin predictors are independent (Durbin-Watson=1.74).

Being age $>24$ months Children age was positively associated with their haemoglobin concentration $(\mathrm{B}=0.17, \mathrm{P}<0.001)$ in which average haemoglobin concentration increases by $0.172 \mathrm{mg} / \mathrm{dl}$. Also, there was a positive association between height of children and their haemoglobin concentration $(\mathrm{B}=0.167, \mathrm{P}=0.0001)$, this had potentially increase haemoglobin concentration by $0.167 \mathrm{mg}$. HAZ had a positive association with increasing haemoglobin concentration by $0.105 \mathrm{mg} / \mathrm{dl}$ while children HAZ score increased $(B=0.105, p=0.010)$. But, mid upper arm circumference (MUAC) had a negative association with haemoglobin concentration, that MUAC increases would decrease haemoglobin concentration $(B=-0.11, p=0.012)$ (Table 6).

Table 6: Linear logistic regression model predicting variables either have positive or negative or no association in increasing the haemoglobin concentration in $\mathrm{mg} / \mathrm{dl}$ among children in Central Highland of Ethiopia.

\begin{tabular}{|l|r|r|r|r|}
\hline & & & \multicolumn{2}{|c|}{ Collinearity Statistics } \\
\cline { 4 - 5 } Variables & \multicolumn{1}{|c|}{$\mathrm{P}$} & $\mathrm{B}(95.0 \% \mathrm{CI})$ & Tolerance & \multicolumn{1}{c|}{ VIF } \\
\hline Age of mother or care giver & .670 & $0.015(-0.012,0.019)$ & 0.731 & 1.369 \\
\hline Household Income In year & .474 & $0.022(0.000,0.000)$ & 0.967 & 1.034 \\
\hline Family Size & .118 & $0.050(-0.012,0.103)$ & 0.907 & 1.103 \\
\hline No. Children born alive & .320 & $-0.035(-0.100,0.033)$ & 0.758 & 1.320 \\
\hline Age of the children & .0001 & $0.172(0.01,0.33)^{*}$ & 0.405 & 2.466 \\
\hline Duration of breastfeed in months & .320 & $0.033(-0.006,0.018)$ & 0.871 & 1.149 \\
\hline Starting time complementary food & .378 & $0.028(-0.016,0.041)$ & 0.958 & 1.044 \\
\hline WFH-Z-score & .704 & $0.014(-0.053,0.079)$ & 0.708 & 1.413 \\
\hline HFA: Z-score & .010 & $0.105(0.02,0.144)^{*}$ & 0.563 & 1.775 \\
\hline Weight in kg & .005 & $0.066(-0.003,0.057)$ & 0.682 & 1.866 \\
\hline Height in cm & .0001 & $0.170(0.14,0.329)^{*}$ & 0.765 & 1.000 \\
\hline MUAC & 0.012 & $-0.111\left(-0.20,-0.025^{*}\right.$ & 0.877 & 1.139 \\
\hline
\end{tabular}

P, p-value; B, B-coefficient; CI, confidence interval; MUAC, Mid Upper Arm Circumference; VIF, Variance Inflation factors; WFH, Weight for Height; HFA, Height relative to age, Note Book $(\mathrm{NB})^{*}$ significant $(\mathrm{P}<0.05)$.

\section{Discussion}

This study showed that the prevalence of anaemia among children of age 6 to 59 months group was lesser (18.2\%) than findings in the 2016 and 2011 report in the Ethiopian Demographic Health Survey (EDHS) which reported 56\% and $44 \%$ in that order of five years trend of anaemia (EDHS, 2016, 2011). However, a study conducted in the districts of Kilte Awulaelo Northern Ethiopia, the prevalence of anaemia among children was 37.3\% which has comparable finding with the current study (Gebremedhin et al., 
2014). However, the prevalence of anaemia among children in developed and in some transition courtiers were low 16\% (12-22) than our finding ( Stevens et al., 2013).

Our finding showed that the mean haemoglobin concentration was greatly improved $(12.55 \pm 1.73 \mathrm{mg} / \mathrm{dl})$ than Global, regional and national haemoglobin concentration $(11.1 \mathrm{mg} / \mathrm{dl}(11.0-11.3 \mathrm{mg} / \mathrm{dl})$ report, but far lower than among high income countries (13.0 (12.8-13.2)) (Stevens et al., 2013). However, the foundation of this study was large study area and study subjects who have high exposure for anaemia and these can strength the validity for the accuracy of finding to estimate the current, true prevalence of anaemia and $\mathrm{Hb}$ concentration.

In this study, one of the determinant factors of anaemia was children age. Higher proportion of young children (6 to <24 months) had $24.1 \%$ anaemia when compared to those 24-59 months old (12.3\%). This study finding was consistent with the EDHS report in 2016, where young children were more $(77 \%)$ likely to be anaemic and this prevalence decreased to $40 \%$ among older children (EDHS, 2016). Similarly, LISBÔA et al (2015) found out that, $43.0 \%$ of young children aged 6 to 24 months in the state of Minas Gerais, Brazil had anaemia compared to children who were aged 24 to 59 months where $32.9 \%$ had anemia.

Hence, this study finding has relatively less prevalence of anaemia and higher $\mathrm{Hb}$ concentration might indicate the presence of extension health workers in the study area. However, a lot of work remains to be done to encourage mothers or caregivers to learn more infantile and young child feeding to prevent anaemia from those risk groups.

In this study, young children who had only been fed cow milk as complementary food were more (49.41\%) anaemic than those who had not. Milk contains low iron (about 0.2 to $0.5 \mathrm{mg} / \mathrm{l}$ ) which might not meet the requirement for young children. Especially, when milk consumption was infrequent without alternative complementary feed could lead children into inferior quality of life (WHO, 1998).

The introduction of cow milk with the long duration of feeding at early age of children became the most important dietary risk factor for anaemia (Male et al., 2001). Also, milk contained micronutrients (casein, whey proteins and calcium) that potentially inhibit the absorption of minute iron found in cow's milk (Hallberg et al, 1992). Furthermore, children less than $<24$ months, particular those under 12 months old are at risk of iron deficiency anemia, due to not consuming animal source of foods (liver, meat and fish) which are rich in iron (WHO, 1998). The WHO report has consistence with our study finding that most of the mothers/caregivers do not feed these foods to their young children; instead households regularly provided cow milk which was produced in large amount and accessed in households and neighbourhoods. Likewise, 
pattern of dietary intake problems among young children can increase risk of anaemia and other nutritional problems. Therefore, BCC intervention might only be able to avoid threat of cow milk conception.

Among the study participants, the intake of fruits and animal sources of foods were less and had significant association with anemia. Similarly, Aspuru et al (2011) reported that dietary factors that can influence poor iron absorption from the diet were several and affect the bioavailability of iron. Consuming meat and vitamin $\mathrm{C}$ and vegetables are major dietary factors that enhance the potential availability of iron for mucosal uptake. Fruits such as lumen, orange ripe mangoes/papayas and pineapple are facilitating iron absorption (Hallberg 1981). But, community found in rural area had less knowledge to take in behavioural change to promote intake of iron-containing foods and enhancers of iron absorption become under question for feature intervention.

Differently, in this study high proportion of children had tea or coffee intake pattern with or after meal has association with anemia. Itske $\mathrm{M}$ et al (200) reasonably reported that the effects of tea consuming with or after meal has specifically been determined on impact of iron absorption and this was principally measured.

\section{Conclusions}

This study delighted that the prevalence of anaemia among children was mild (18.2\%), but pragmatically moderate among children age 6- <24 months old. Children who consumed cow milk regularly as complementary food and age 6- <24 months old were significantly associated with anemia. Children who had better height (longer) and older age had increased their $\mathrm{Hb}$ concentration at list by $0.17 \mathrm{gm} / \mathrm{dl}$ compared to those had height short (low height) and younger age children.

The dietary intakes of children were also a traditional and Mothers/caregivers knowledge for complementary food was very less. High proportion of children age 6- $<24$ months old regularly consumed cow milk as complementary food. Low proportion of mothers/caregivers confirmed that their children had consumed animal source of foods, used fruits that facilitate absorption and avoided inhibitor factors.

It is important to deliver sufficient information that provide knowledge for mothers/ caregivers about the source of foods which have iron-rich or fortified, Although, BCC has to deliver knowledge that appropriate for the preparation and feeding of infants and young children to prevent iron deficiency anemia. Through the BCC intervention program encouraging mothers/ caregivers to take behavioral change communication that promote intake of iron-containing foods, such as meat and organs from cattle and fowl for the young children. 
We recommended to the community to use foods that enhance iron absorption from diet such as lumen, orange ripe mangoes/papayas and pineapple are fruits that facilitate iron absorption. Additionally, introduce mothers/ caregivers the need of preventing meal patterns like cow milk that favouring for inhibition of iron absorption rather than other adverse effect.

\section{Acknowledgements}

We would like to express their gratitude to Jimma University for financial support and ethical approval. We extend our special gratitude to Central highland provinces (Arsi and Bale), Munesa, Asella, Limuna Bilalo, Digeluna Tijo, Honkolo Wabe Health Offices for their administrative, technical and material support. Finally, we thank the study participants and health extension workers for their involvement in the study.

\section{Ethical approval}

This research was approved by Ethical Review Committee of Jimma University. Letter of permission was obtained from Arsi Zone administrative and health department offices. At the end, we obtained permission from 8 district administrative offices 16 Kebeles (Smallest Administrative Units) which were site for data collection administrations offices. In addition, all of the study participants (children's mothers/ caregivers) were informed about the purpose of the study.

\section{Funding}

The research was fully funded by Jimma University.

\section{Competing interests}

None declared.

\section{Author Contribution}

A. Ferede: The conception of the design of the research project, data collection, data entry, analysis, preparation and write up manuscript and appraisal. Belachew T., and M. Abera participated in the analysis of data, write up and preparation of manuscript for publication. All authors read and approved the final manuscript I read and approved the final manuscript for publication.

\section{References:}

1. Aklilu Mekasha,Lisanework Nigatu, Kindie Tesfaye, Alan J. (2013) Duncan $^{\mathrm{c}}$ Modeling the response of tropical highland herbaceous grassland species to climate change: The case of the Arsi Mountains of Ethiopia: Biological Conservation 168, 169-175 
2. Aukett MA, Parks YA, Scott PH, Wharton BA (2003). Treatment with iron increases weight gain and psychomotor development. Arch Dis Child. 1986; 61:849-57. PMC

3. Black MM. Micronutrient deficiencies and cognitive functioning. J Nutr.; 133:3927S 3931S.

4. Castro Lisbôa, Oliveira, Lamounier, Mariano Silva, Renata Nascimento Freitas (2015). Prevalence of iron-deficiency anaemia in children aged less than 60 months:; Apopulation-based study from the state of Minas Gerais, Brazil. Rev. Nutr., Campinas, 28(2):121-131, mar./abr.

5. Central Statistical Agency Ethiopia (2016) Ethiopia Demographic and Health Survey https://dhsprogram.com/pubs/pdf/FR328/FR328. Accessed October 2017

6. Central Statistical Agency Ethiopia (2012) Ethiopia Demographic and Health Survey. info@measuredhs.com:http://www.measuredhs.com: Accessed November 2015

7. Gebremedhin Gebreegziabiher, Belachew Etana and Daniel Niggusie (2014) Determinants of Anaemia among Children Aged 6-59 Months Living in Kilte Awulaelo Woreda, Northern Ethiopia; Hindawi Publishing Corporation Anemia, ID 245870, http://dx.doi.org/ 10.1155/2014/245870

8. Grantham-McGregor SM, Ani CC (1999) the role of micronutrients in psychomotor and cognitive development. Br Med Bull: 55:511-527.

9. Gretchen A Stevens, Mariel M Finucane, Luz Maria De-Regil et al.,( 2013) Global, regional, and national trends in haemoglobin concentration and prevalence of total and severe anaemia in children and pregnant and non-pregnant women for1995-2011: a systematic analysis of population-representative data; on behalf of Nutrition Impact Model Study Group (Anemia). www.the lancet. com/lancetgh Vol 1

10. Hallberg L (1981) Bioavailable nutrient density: A new concept applied in the interpretation of food iron absorption data; American Journal of Clinical Nutrition 34(10):2242-7.

11. Hallberg L, Rossander-Hultén L, Brune M, Gleerup A (1992) Calcium and iron absorption: mechanism of action and nutritional importance. Eur J Clin Nutr.46:317-27.

12. Hiroko KODAMA, 2004 Trace Element Deficiency in Infants and Childre-Clinical practice: JMAJ 47(8): 376-381,

13. Itske M , Lilian B. M. Tijburg Onno Korver (2000) Effect of Tea and Other Dietary Factors on Iron Absorption: Food Science and Nutrition 40(5):371-98. 
14. Kattalin Aspuru , Carlos villa, Fernando Bermejo et al., (2011) Optimal management of iron defiiency anaemia due to poor dietary intake: International Journal of General Medicine:4 741-750

15. Male C, Persson LA, Freeman V, et al (2001) Prevalence of iron deficiency in 12-month old infants from 11 European areas and influence of dietary factors on iron status (Euro-Growth study). Acta Paediatr;90:492-8.

16. Mayo Clinic , 2016 Iron deficiency anaemia for proper growth and development https://www.mayoclinic.org/diseases-conditions/irondeficiency-anemia/symptoms-causes/syc-20355034N. Accessed December 2017.

17. National Statistical Office (NSO) of Malawi (2010) Malawi Demographic and Health Survey https://dhsprogram.com/pubs/pdf/fr247/fr247. Accessed September 2017.

18. Sánchez Brevers A. Monografía Sobre la, (2014) Anaemia Ferropénica. University of Cantabria (Spain); Neuropsychiatr Dis Treat ; 10: 2087-2095

19. Uganda Bureau of Statistics (UBOS) (2006) Uganda Demographic and Health Survey (UDHS)https://www.dhsprogram.com/pubs/. Accessed September 2017.

20. World Health Organization, (2011) Haemoglobin concentrations for the diagnosis of anaemia and assessment of severity. Vitamin and Mineral Nutrition Information System. Geneva, World Health Organization, $\quad$ (WHO/NMH/NHD/MNM/11.1). http://www.who.int/vmnis/indicators/haemoglobin: accessed September 2015.

21. World Health Report 2002: reducing risks, promoting healthy life: overview. Geneva, World Health Organization, 2002 (WHO/WHR/02.1). $\quad$ http://whqlibdoc.who. Int/publications/2008/9789241596657. Accessed December 2010.

22. World Health Organization (1998) Complementary feeding of young children in developing countries. A review of current scientific knowledge. Geneva:

WHO: http://apps.who.int/iris/handle/10665/65932. Accessed October 2012.

23. World Health Organization Expert Committee on Physical Status (1995) Physical status: the use and interpretation of anthropometry: report of a WHO Expert Committee. Geneva: World Health Organization; https://www.who.int/childgrowth/publications/physical status/en/: Accessed October 2012 